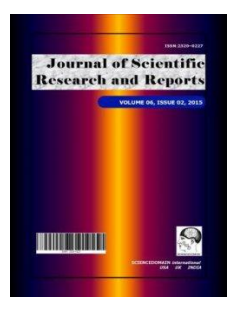

Journal of Scientific Research \& Reports

14(2): 1-8, 2017; Article no.JSRR.33641

ISSN: 2320-0227

SCIENCEDOMAIN international

www.sciencedomain.org

\title{
The Effect of Sodium Silicate on the Behaviour of Shotcretes for Tunnel Lining
}

\author{
Luigi Coppola ${ }^{1}$, Alessandra Buoso ${ }^{1}$, Denny Coffetti ${ }^{1}$, Patricia Kara ${ }^{2^{*}}$, \\ Sergio Lorenzi ${ }^{1}$ and Franco D'Alessandro ${ }^{3}$ \\ ${ }^{1} D I S A$, University of Bergamo, Dalmine (BG), Italy. \\ ${ }^{2} E M I B$, Faculty of Applied Engineering, University of Antwerp, Belgium. \\ ${ }^{3}$ BASF C.C. Underground Construction, Treviso (TV), Italy.
}

\begin{abstract}
Authors' contributions
This work was carried out in collaboration between all authors. Author LC designed the study. Authors $A B, D C$ and FDA performed the statistical analysis and wrote the protocol. Authors PK and SL managed the analyses of the study, the literature searches, wrote the first draft of the manuscript. All authors read and approved the final manuscript.
\end{abstract}

Article Information

DOI: $10.9734 / J S R R / 2017 / 33641$ Editor(s):

(1) Luigi dell'Olio, School of Civil Engineering, Channels and Ports, University of Cantabria, Cantabria, Spain. (2) Luigi Rodino, Professor of Mathematical Analysis, Dipartimento di Matematica, Università di Torino, Italy. Reviewers: (2) Halil Görgün, Dicle University, Turkey. (3) Leo Baldenegro, Center of Engineering and Industrial Development, Mexico. Complete Peer review History: http://www.sciencedomain.org/review-history/19001

Case Study

Received 24 $4^{\text {th }}$ April 2017

Accepted $4^{\text {th }}$ May 2017

Published $10^{\text {th }}$ May 2017

\begin{abstract}
Present case study investigates the rheological, mechanical and in-placing performances of fiberreinforced shotcrete manufactured with different fibers (steel, glass and polypropylene) and with sodium silicate based set-accelerating admixture for tunnel linings. The study compares the performances of concretes manufactured and fully compacted with those shotcretes which are manufactured directly on the job-site. The influence of sodium silicate accelerator on mechanical and rheological properties of fiber-reinforced shotcretes with respect to reference concrete were evaluated. It was observed that: The addition of fibers does not influence slump and workability retention with respect to reference concrete, independent of type and dosage of fibers; Spraying and set accelerator dosage determined a decrease about of $10-30 \%$ in compressive strength compared to that of concrete placed and vibrated without sodium silicate accelerator; The setaccelerating admixture has negative effect on compressive strength of fiber-reinforced shotcrete (15\%).
\end{abstract}


Keywords: Sodium silicate based set-accelerating admixture; mechanical and rheological properties.

\section{INTRODUCTION}

Sprayed concrete, or shotcrete, is used worldwide to construct tunnels or underground structures. The poured mix must set quickly in order to stabilize the structure [1-2]. The important basic requirements of shotcrete are good adhesiveness, a low amount of rebounding, good shooting, and the quick formation of initial strength [3-4]. To meet these requirements, accelerators have become a fundamental additive in shotcrete to achieve appropriate initial strength, reduce rebound, and suppress early ground relaxation. This affects not only the early strength of the shotcrete but also the development of long-term strength, durability and thickness. Traditionally, shotcrete's quick-setting properties have been achieved by the injection of high-alkaline additives at the spraying nozzle. Accelerating admixtures are composed of chemicals that influence the rate of cement hydration, thereby shortening the setting time and, in some cases, increasing the rate of early strength development [3]. Set accelerators affect both the $\mathrm{C}_{3} \mathrm{~A}$ hydration (by interfering with the $\mathrm{C}_{3} \mathrm{~A}$ - gypsum reaction) and the $\mathrm{C}_{3} \mathrm{~S}$ hydration (aiding the dissolution of lime) [5-6]. However, this method resulted in concrete with high porosity and density, low strength and durability, and environmental concerns.

Nowadays, shotcrete accelerators are classified as silicate-, aluminate-, or alkali-free, cementbased minerals, depending on the main material that is present. The sodium silicate accelerator gives a rapid initial set and a slow final set, while the aluminate accelerator provides a slow initial set and a fast final set. Both types suffer the same deficiency of loss in strength and durability over the long term. Furthermore, their strong alkalinity may endanger workers and lead to environmental contamination. Increasing the accelerator amount adds to the cost and also increases the rebound ratio $[1,7]$. To mitigate these issues, alkali-free and cement-based mineral accelerators (CMs) that are environmentally friendly and provide good longterm strength are now frequently used in construction sites. Sodium silicate based admixtures are more effective - in terms of set acceleration - and cheaper than alkali-free products. For these reasons, sodium silicate accelerators are widely used in tunnel linings. However, a very fast increase of early strength development in sodium-accelerated shotcretes is followed by a sharp reduction of mechanical properties of concrete at later ages.

For many years, fibers of different nature have been used to reinforce shotcrete in tunneling applications. Several research investigations have ascertained the significant effect of fiber addition on ductility and punching resistance of tunnel segments and shotcrete panels [8]. Currently, concrete is reinforced by using steel, glass, polypropylene or acryl-nitrile fibers and carbon nanotubes in order to assess the stress level in reinforced concrete elements [9-13]. To improve durability in severe conditions and to favor replacement of temporary solutions requiring subsequent cuttings glass fibers and glass fabric solutions are used [8,14-16]. To increase fire resistance and prevent explosive spalling of concrete cover polypropylene fibers are used [17]. Compared with traditional steel mesh, fibers arrange themselves in threedimensional directions inside the cement matrix and they are able to absorb the tensile stress induced by shrinkage and thermal gradients. Therefore, fibers could limit crack width and increase the energy absorption capacity (toughness) of the material [18]. In particular, fibers determine a considerable improvement in the post-cracking behavior of concrete [19]. Reference concrete fails suddenly once the deflection corresponding to the ultimate flexural strength is exceeded; On the other hand, fiberreinforced concrete continues to sustain considerable loads even at deflections considerably in excess of that of the reference concrete. So, compared to reference concrete, fiber-reinforced concrete is tougher and more resistant to impact [18], permitting control of the local detachment of tunnel linings [7,20-21].

The paper presents research results on rheological and mechanical properties of reference and fiber - reinforced shotcretes manufactured with sodium silicate accelerator and glass, steel and polypropylene fibers.

\section{EXPERIMENTAL INVESTIGATION}

\subsection{Materials}

Limestone Portland cement (CEM II/A-LL 42.5R) according to EN 197-1 was used. The chemical composition of cement is shown in Table 1. Coarse-grained sand $(40 \%$ of the total mass of the aggregates) and crushed sand (25\%) were 
used as fine aggregates. In addition, crushed stone (max size $8 \mathrm{~mm}$ ) was used as coarse aggregate $(35 \%)$. A sieve analysis of fine and coarse aggregates is shown in Table 2.

Table 1. Chemical composition (\% by mass) of the cement (CEM II/A-LL 42.5R)

\begin{tabular}{ll}
\hline & CEM II/A-LL 42.5R \\
\hline Loss of ignition, \% & 0.88 \\
$\mathrm{SiO}_{2}, \%$ & 19.31 \\
$\mathrm{Al}_{2} \mathrm{O}_{3}, \%$ & 4.31 \\
$\mathrm{CaO}, \%$ & 61.08 \\
$\mathrm{MgO}, \%$ & 2.38 \\
$\mathrm{SO}_{3}, \%$ & 2.96 \\
$\mathrm{Na}_{2} \mathrm{O}, \%$ & 0.29 \\
$\mathrm{~K}_{2} \mathrm{O}, \%$ & 0.86 \\
$\mathrm{TiO}_{2}, \%$ & 0.14 \\
$\mathrm{Fe}_{2} \mathrm{O}_{3}, \%$ & 2.28 \\
\hline
\end{tabular}

Combined aggregate grading is presented in Fig. 1. A polycarboxylate-based superplasticizer with dosage $1.4 \%$ vs. cement mass was used $[6,22]$. Sodium silicate accelerator was used as a setaccelerating admixture. The dosage of sodium silicate accelerator was in the range of $13 \%$ $17 \%$ vs. cement mass and it was added in the nozzle during spraying. The w/c was equal to 0.44 . Workability of reference concrete was measured by slump test according to EN 123502 and the consistency class required for the mix was S5 (slump $\geq 220 \mathrm{~mm}$ ). The composition of reference concrete without fibers and setaccelerating admixture is shown in Table 3.

In order to compare the influence of different types and dosages of fiber reinforcement on rheological and mechanical properties of shotcrete with respect to reference concrete (without fibers: PL), steel fibers (SF), glass fibers
(GF) and polypropylene fibers (PF) were added to the mix. The main properties of fibers are listed in Table 4. The amount of fibers added to the concrete mixes is shown in Table 5. The dosage by volume of steel and glass fibers is very similar; Consequently, rheological and mechanical properties are directly comparable establishing the efficiency of the two types of fibers. The dosage of polypropylene fibers is lower than that used for the steel and glass fibers (about 37\% and 39\% lower, respectively). During casting (at $1 / 5$ and $4 / 5$ of the placing), before the addition of set-accelerating admixture, the workability and the density were evaluated in order to investigate the fiber influence on rheological properties of the concrete. The fiber content and the shotcrete rebound were measured according to EN 14488-7.

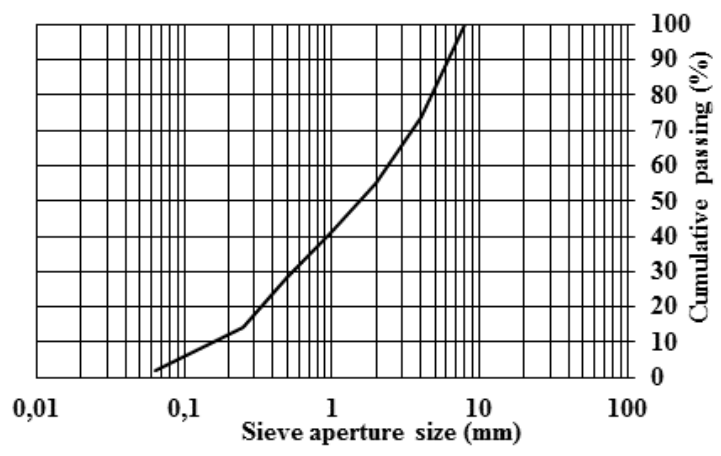

Fig. 1. Aggregates grading

\subsection{SPECIMENS}

Test panels with and without the addition of setaccelerating admixture were manufactured to evaluate hardened concrete properties according to EN 14488. The panels were manufactured by spraying the set-accelerated admixture in order

Table 2. Sieve analysis of aggregates in shotcrete

\begin{tabular}{lllll}
\hline Square mesh - $\mathbf{m m}$ & \multicolumn{4}{c}{ Cumulative per cent passing [\%] } \\
\cline { 2 - 5 } & $\begin{array}{l}\text { Crushed sand } \\
\mathbf{( 2 5 \% )}\end{array}$ & $\begin{array}{l}\text { Coarse-grained } \\
\text { sand } \mathbf{( 4 0 \% )}\end{array}$ & $\begin{array}{l}\text { Crushed stone } \\
\mathbf{( 3 5 \% )}\end{array}$ & $\begin{array}{l}\text { Total } \\
\mathbf{( 1 0 0 \% )}\end{array}$ \\
\hline 16.0 & 100.0 & 100.0 & 100.0 & 100.0 \\
12.5 & 100.0 & 100.0 & 100.0 & 100.0 \\
8.0 & 100.0 & 100.0 & 100.0 & 100.0 \\
4.0 & 100.0 & 99.0 & 26.0 & 73.7 \\
2.0 & 78.0 & 87.0 & 1.7 & 54.9 \\
1.0 & 54.0 & 69.0 & 0.5 & 41.3 \\
0.5 & 38.0 & 47.0 & 0.2 & 28.4 \\
0.25 & 25.0 & 20.0 & 0.2 & 14.3 \\
0.063 & 4.9 & 1.2 & 0.2 & 1.8 \\
\hline
\end{tabular}


Table 3. Composition and principal characteristics of reference concrete

\begin{tabular}{lll}
\hline Cement CEM II/A-LL 42.5R & $\mathrm{kg} / \mathrm{m}^{3}$ & 450 \\
\hline Water & $\mathrm{kg} / \mathrm{m}^{3}$ & 200 \\
Aggregates: & $\mathrm{kg} / \mathrm{m}^{3}$ & 410 \\
Crushed sand & $\mathrm{kg} / \mathrm{m}^{3}$ & 650 \\
Coarse-grained sand & $\mathrm{kg} / \mathrm{m}^{3}$ & 575 \\
Crushed stone (max size 8mm) & $\% \mathrm{vs} \mathrm{c.m}$. & 1.4 \\
Superplasticizer & $1 / \mathrm{m}^{3}$ & 6.3 \\
& $\%$ & 2.5 \\
Entrapped air & $1 / \mathrm{m}^{3}$ & 25 \\
& & 0.44 \\
Water/Cement & $\mathrm{kg} / \mathrm{m}^{3}$ & 2344 \\
Specific mass & & \\
\hline
\end{tabular}

Table 4. Principal characteristics of fibers

\begin{tabular}{lllll}
\hline Abbreviation & Material & Length $-\mathbf{m m}$ & Diameter $-\mathbf{m m}$ & I/d \\
\hline SF & Steel & 33 & 0.55 & 60 \\
GF & Glass & 40 & 1.6 & 25 \\
PF & Polypropylene & 40 & 0.9 & 44 \\
\hline
\end{tabular}

Table 5. Type and dosage of fiber added to reference mix

\begin{tabular}{llllc}
\hline Mix & Fiber type & \multicolumn{2}{c}{ Specific mass } & Fiber dosage \\
\cline { 3 - 5 } & & $\mathbf{k g} / \mathbf{m}^{3}$ & $\mathbf{k g} / \mathbf{m}^{3}$ & $\mathbf{1 / \mathbf { m } ^ { 3 }}$ \\
\hline $\mathrm{PL}$ & - & 2341 & - & - \\
$\mathrm{SF}$ & Steel & 2394 & 38.2 & 4.4 \\
$\mathrm{GF}$ & Glass & 2342 & 11.2 & 4.7 \\
$\mathrm{PF}$ & Polypropylene & 2324 & 3.5 & 2.9 \\
\hline
\end{tabular}

to evaluate the energy absorption capacity after 1,7 and 28 days. For reference mix (without fibers), a steel mesh (diameter: $6 \mathrm{~mm}$; Spacing: $150 \mathrm{~mm}$ ) was used as reinforcement. In order to avoid water evaporation the panels were immediately wet cured after casting. Afterward, the specimens were cured on site conditions until they were cored according to EN 14488-1:2005. Three cylindrical specimens $(d=100 \mathrm{~mm}$, $\mathrm{h}=100 \mathrm{~mm}, \mathrm{~h} / \mathrm{d}=1$ ) for each panel were obtained. The density and compressive strength of the hardened concrete at $1,7,14$ and 28 days were measured in accordance with EN 12390-2.

\section{RESULTS AND DISCUSSION}

Fig. 2 shows the average values of density of fresh concrete which were measured after $1 / 5$ and $4 / 5$ of the dumping, before the setaccelerating admixture was added.

The values are similar for all the mixes, independent of the type of fiber used. It can be noted that fibers do not determine any anomalous air entrapment. The target workability (S5 according to EN 206-1) was attained without any increase in water demand with respect to the reference concrete for all the fiber-reinforced mixes, independent of the type of fiber. Moreover, no slump loss was noticed at $1 / 5$ of the dumping (see Fig. 3).

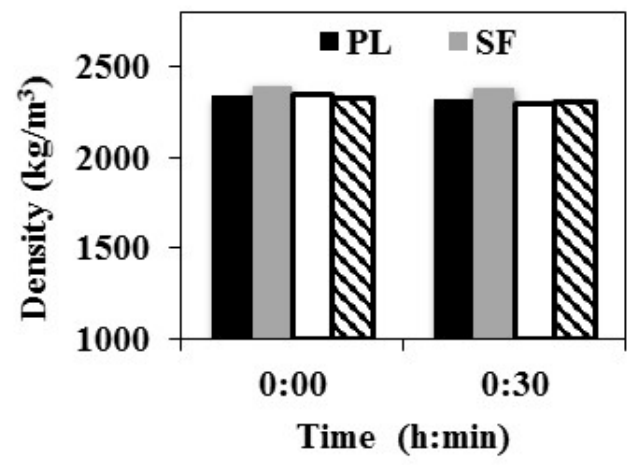

Fig. 2. Density of fresh concrete vs. time

Fig. 4 shows the shotcrete rebound index and the set-accelerating admixture dosage. The lower dosage of sodium silicate accelerator was used for the steel fiber-reinforced shotcrete and the higher one for glass fiber-reinforced 
shotcrete. The reference and the polypropylene fiber-reinforced shotcretes required a similar setaccelerating admixture dosage (about 15\%). The shotcrete rebound varied between 18 and $35 \%$ for the mixes.

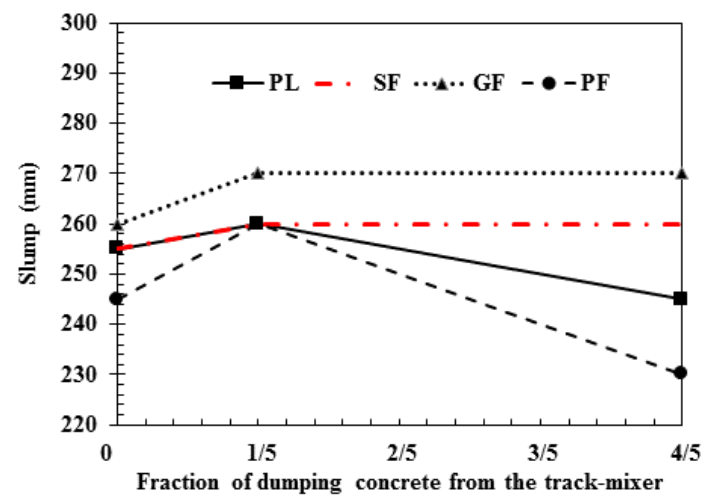

Fig. 3. Slump vs. time

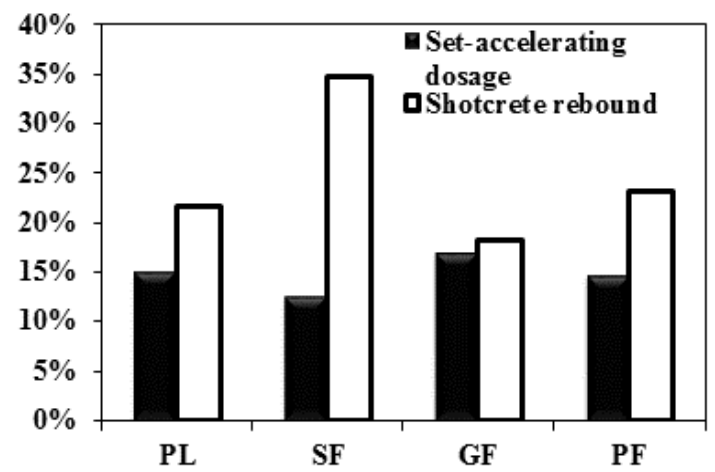

Fig. 4. Set-accelerating admixture dosage and shotcrete rebound

Set-accelerating admixture and the spraying operation determines a reduction of density in the range $2-6 \%$ with respect to the mixes without sodium silicate accelerator, which were poured and vibrated independent of curing time and type of fibers (see Fig. 5). It can be noticed that the density of hardened mix is substantially equal or higher than that of the reference shotcrete without fibers.

Fig. 6 summarizes the compressive strength values as a function of time for concretes (placed and vibrated) and shotcretes (sprayed) without and with the set-accelerating admixture, respectively. After 1 day, the compressive strength of shotcrete with the addition of setaccelerating admixture is higher (50 to $85 \%$ ) than that of poured and vibrated concrete mixes without the sodium silicate accelerator, independent of the fiber reinforcement. The compressive strength at the age of 2 days is very similar for all the mixes.

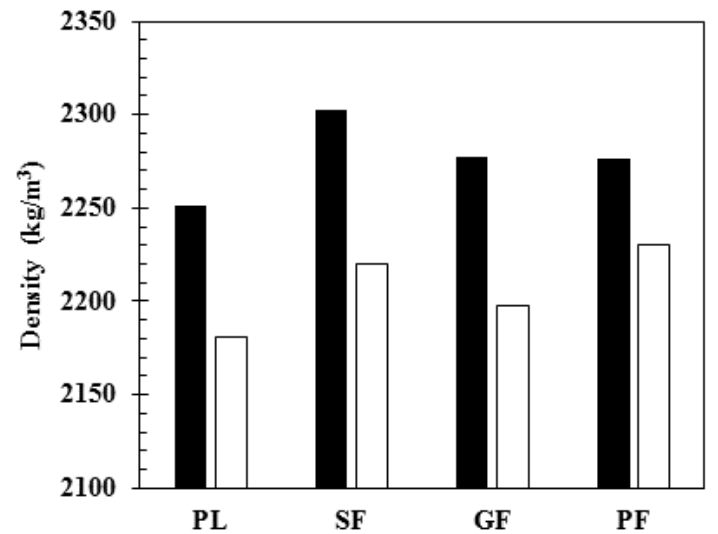

Fig. 5. Density of hardened concretes and shotcretes after 28 days

The positive effect of set-accelerating admixture is equal to the negative effect due to the increase in porosity as a consequence of spraying. After 28 days, shotcretes with sodium silicate accelerator show lower compressive strength, between 25 and $45 \%$ less than that of vibrated concrete without set-accelerating admixture. In particular, a minor decrease (about 25\%) is observed for steel fiber shotcrete, manufactured using the lowest set-accelerating admixture dosage. The greatest gap in the compressive strength was detected for glass fiber shotcrete, containing the highest set-accelerating admixture dosage. It can be seen that the compressive strength values depend on set-accelerating admixture dosage rather than on type and dosage of fibers. However, widespread experience in the industry has shown that different fiber types display very different levels of rebound, commonly fibers are added to improve tensile/flexural strength and postcracking behavior. Bond strength was not measured in this study. In general terms, considering that the reduction of compressive strength due to spraying is about $5 \%$ for each percent decrease in density and taking into account that the density reduction is about $2-6 \%$, the reduction of compressive strength due to spraying should be about $10-30 \%$. So, if the compressive strength decrease is between 25 and $45 \%$, the set-accelerating admixture effect on reduction of mechanical properties is about $15 \%$. 


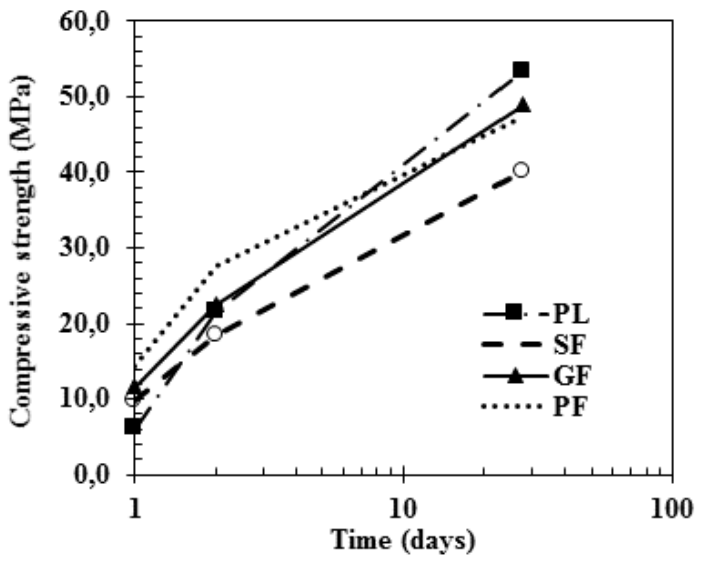

a)

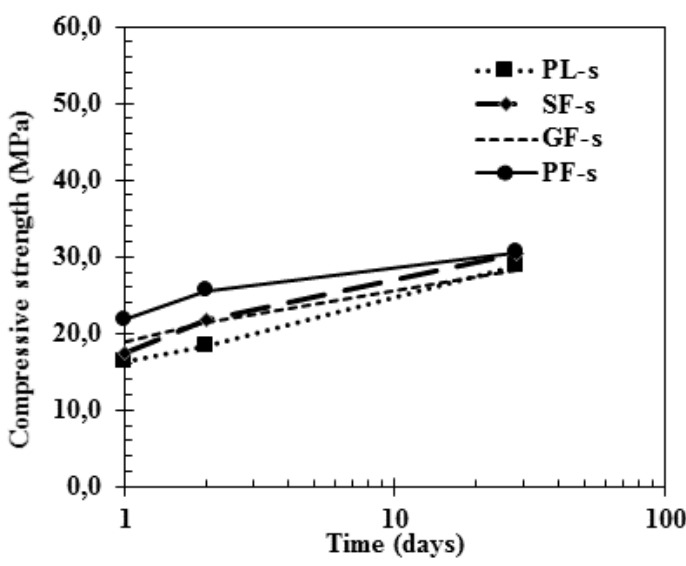

b)

Fig. 6. Compressive strength vs. time for poured and vibrated specimens (a) and for set accelerated and sprayed (b)

The results of punching tests (see Fig. 7) are shown in terms of deformation energy of the panels manufactured: with set-accelerated admixture shotcretes containing fibers and with the set-accelerated admixture reference concrete reinforced by a steel wire mesh (diameter: $6 \mathrm{~mm}$; spacing: $150 \mathrm{~mm}$ ). Results indicate that fibers do not guarantee the same performance as steel mesh. In fact, after 1 day, the shotcrete reinforced by steel mesh exceeds the minimum value of 500 Joules required by the standard. By contrast, this value is attained using steel, glass and polypropylene fibers only at the age of 28 days. It is important to underline that the polypropylene fibers shotcrete mix was manufactured with a fiber dosage $\left(2.9 \mathrm{l} / \mathrm{m}^{3}\right)$ lower than that used for steel fiber and glass fiber shotcretes (respectively 4.4 and $4.7 \mathrm{I} / \mathrm{m}^{3}$ ). In conclusion, results pointed out that the better punching behavior is for steel reinforced shotcrete than for fiber-reinforced shotcrete. This could be explained by the fact that the shotcrete behavior in punching tests depends not only on the fiber type and dosage, but also on the matrix quality, a continuous steel mesh or short fibers. In this research, a hypothesis, that the addition of set-accelerating admixture has caused a worsening of matrix quality and consequently a reduction of the bonding between fibers and shotcrete, could be investigated in further research. The toughness behavior and the energy absorption of fiber-reinforced mixes have decreased. The difference between fiberreinforced and steel mesh reinforced shotcretes increased.

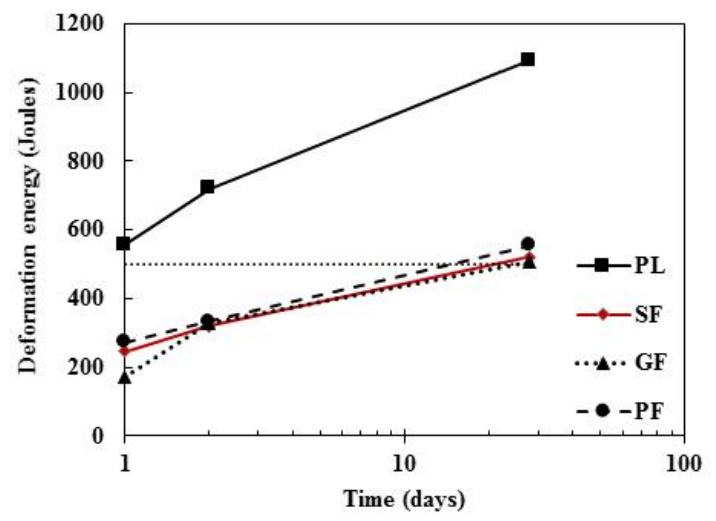

Fig. 7. Deformation energy vs. time

\section{CONCLUSION}

This paper presents research results regarding the use of different fibers (steel, glass and polypropylene) in reinforced shotcretes manufactured with a sodium silicate based setaccelerating admixture for tunnel linings. The influence of sodium silicate accelerator on mechanical and rheological properties of fiberreinforced shotcretes with respect to reference concrete were evaluated. Based on the results of this experimental investigation, the conclusions are as follows:

1. The addition of fibers does not influence slump and workability retention with respect to reference concrete (PL), independent of type and dosage of fibers.

2. The density of hardened shotcrete and compressive strength at the age of 28 days decreases when adding set-accelerating admixture. After 28 days, shotcretes with sodium silicate accelerator show 
compressive strength lower (in the range of $25-45 \%$ ) compared to fully compacted concrete without set-accelerating admixture. In particular, compressive strength decreases by $10-30 \%$ as a consequence of spraying. The setaccelerating admixture has negative effect on compressive strength of fiber-reinforced shotcrete (decrease is about 15\%).

3. The toughness behavior and the energy absorption of fiber-reinforced shotcrete are lower than that of steel reinforced mix. However, as the recommendation, it could be improved if the dosage rate of fibers and the depth of mesh in the shotcrete cross-section which strongly influences the apparent performance, would be considered in the further investigation.

\section{ACKNOWLEDGEMENTS}

The authors would like to acknowledge the BASF CC - ITALY for financing this research and for the opportunity to carry out the tests on the jobsite.

\section{COMPETING INTERESTS}

Authors have declared that no competing interests exist.

\section{REFERENCES}

1. Prudencio LR Jr. Accelerating admixtures for shotcrete. Cement Concrete Comp 1998;20(2-3):213-219.

2. Jolin $M$, Beaupré $D$, Pigeon $M$, Lamontagne A. Use of set accelerating admixtures in dry-mix shotcrete. J Mater Civil Eng. 1997;9(4):180-184.

3. Paglia C, Wombacher F, Bohni $H$. The influence of alkali-free and alkaline shotcrete accelerators within cement systems. I. Characterization of the setting behavior. Cement Concrete Res. 2001; 31(6):913-918.

4. De Belie N, Grosse CU, Kurz J, Reinhardt $H W$. Ultrasound monitoring of the influence of different accelerating admixtures and cement types for shotcrete on setting and hardening behavior. Cement Concrete Res. 2005;35:2087-2094.

5. Lea FW. Lea's chemistry of cement and concrete, P.C. Hewlett (Ed.), London, UK; 1998.

6. Ramachandran VS. Concrete admixtures handbook (Second edition): Properties, science and technology. Noyes Publications, USA; 1996.

7. Zaffaroni P, Pistolesi C, Dal Negro E, Coppola L, Collepardi M. Calcestruzzi proiettati ad alte prestazioni / high performance shotcrete. Industria Italiana del Cemento. Italian. 2001;756:598-605.

8. Colombo M, di Prisco M, Mazzoleni L. Sprayed tunnel linings: A comparison between several reinforcement solutions. Mater Struct. 2009;42(9):1295-1311.

9. Coppola L. II Manuale del Calcestruzzo di Qualità; 2008.

10. Coppola L, Buoso A, Corazza F. Electrical properties of carbon nanotubes cement composites for monitoring stress conditions in concrete structures. Appl Mech Mater. 2011;82:118-123.

11. Banthia N. Fiber-reinforced concrete. Mater J. 1995;92(1):48-57.

12. Cordon WA. History of concrete. ACI Special publication. 1974;46:167-176.

13. Douglas KS, Billington SL. Rate dependence in high-performance fiberreinforced cement-based composites for seismic applications. In Proceedings of the $5^{\text {th }}$ International conference on construction materials, ConMat05, Vancouver, BC, Canada; 2005.

14. Zhu W, Bartos PJM. Assessment of interfacial microstructure and bond properties in aged GRC using a novel microindentation method. Cement Concrete Res. 1997;27(11):1701-1711.

15. Mu B, Meyer C. Flexural behaviour of fiber meshreinforced concrete with glass aggregate. ACl Mater J. 2002;99(5):425434.

16. Purnell $P$, Beddows J. Durability and simulated ageing of new matrix glass fibre reinforced concrete. Cement Concrete Comp. 2005;27:875-884.

17. Buttner T, Orlowsky J, Raupach M. Fire resistance tests on textile reinforced concrete under static loading - results and future developments. Proceedings of the fifth international RILEM workshop (PRO53). 2007;361-370.

18. Coppola L, Cadoni E, Forni D, Buoso A. Mechanical characterization of cement composites reinforced with fiberglass, carbon nanotubes or glass reinforced plastic (GRP) at high strain rates. Appl Mech Mater. 2011;82:190-195.

19. Coppola L, Troli R, Collepardi S, Borsoi A, Cerulli T, Collepardi M. Innovative 
cementitious materials from HPC to RPC Part II. The effect of cement and silica fume type on the compressive strength of reactive powder concrete. Industrialtaliana del Cemento. 1996;66:112-125.

20. Zeidler K, Jäger J. Fiber reinforced shotcrete for tunnel linings. In Recent Advances in Concrete Technology: Proceedings of the first International conference, 19-21 September, Washington, DC, USA. 2007;667-678.
21. Coppola L. Rheology proportioning and properties of self-compacting concretes. In Proceedings of Self Compacting Concrete for Tunnel Linings; 2001.

22. Coppola L, Buoso A, Lorenzi S. Compatibility issues of NSF-PCE superplasticizers with several lots of different cement types (long-term results). KueiSuan Jen Hsueh Pao /Journal of the Chinese Ceramic Society. 2010;38(9): 1631-1637.

(c) 2017 Coppola et al.; This is an Open Access article distributed under the terms of the Creative Commons Attribution License (http://creativecommons.org/licenses/by/4.0), which permits unrestricted use, distribution, and reproduction in any medium, provided the original work is properly cited.

Peer-review history:

The peer review history for this paper can be accessed here: http://sciencedomain.org/review-history/19001 